\title{
Recurrent Pancreatic Neuroendocrine Carcinoma
}

National Cancer Institute

\section{Source}

National Cancer Institute. Recurrent Pancreatic Neuroendocrine Carcinoma. NCI

Thesaurus. Code C115433.

The reemergence of pancreatic neuroendocrine carcinoma after a period of remission. 